\title{
Development prospects of the technologies and infrastructure for a transport and logistics system of a new type
}

\author{
Gleb Savin* \\ Ural State University of Economics, 8 Marta St., 62, Yekaterinburg, Russia
}

\begin{abstract}
In contemporary conditions, the transport and logistics system (TLS) is developing in the field of intelligent transportation systems (ITS) and highly automated vehicles (HAV), but to create a unified integrated stream management system it is necessary to search for a new approach, which would reduce the load on infrastructure and decrease transaction costs. And the technologies of the distributed data register, which have the status of "end-to-end" digital technologies, have the opportunity today to combine these spheres in the field of functioning and forecasting the rational choice of optimizing streaming processes, and also ensure the formation of a new TLS type. For its development today, it is necessary to introduce "regulatory sandboxes", which are a general trend for testing ready-made solutions in the field of smart contracts development. At the same time, this approach enables to collect and take into account the consumers' opinions; it also provides a higher level of infrastructure reliability in order to ensure sustainable economic development.
\end{abstract}

\section{Introduction}

A lot of modern technologies [1-4] aim to computerize and develop the digital economy [5], and are also meant to ensure economic growth and intensive improvement in the quality of human life. In this aspect, the transport and logistics system ensures the movement of economic resources and their optimization, and is focused on the development of the corresponding world-class industry, innovations, software, and human competencies.

Today, the leading corporations (Siemens, BMW, Mercedes Benz, IBM, Phillips, General Electric, Apple, Yandex) are developing their intelligent products in transport and logistics systems, and research centers (IBM, McKinsey, Price Waterhouse, etc.) are generating innovative ideas to enhance stream processing with new meanings and approaches of digital improvement.

In addition, in transport and logistics systems, routine operations of interaction between economic agents are being changed, and the elements of intelligent control systems are being introduced.

\footnotetext{
*Corresponding author: glebsavin@ya.ru
} 
Also, as part of implementation of highly automated vehicles [6], technologies and solutions are being improved:

- $\mathrm{V} 2 \mathrm{~V}$ in the field of IEEE 802.bd and NR-V2X standards, DSRC technology in accordance with IEEE $802.11 \mathrm{p}$, ensuring vehicle interoperability;

- ADAS system (LDWS - lane departure warning system, LKAS - lane keeping assistance system, etc.);

- convolutional neural networks $(\mathrm{CNN})$ and recurrent neural networks (RNN) as components of artificial intelligence that identify the roads and its parameters;

- systems of deep learning and reinforcement learning (DRL) as forms of machine learning;

- computer vision (road models, etc.).

But today, in transport and logistics systems, with the trusted competence center being developed, technologies of distributed database systems [7-9] are not fully implemented, and the formation of an open architecture with a dynamic principle of infrastructure development is not ensured, which could provide a more efficient stream management and a lower level of transaction costs.

\section{Materials and Methods}

The Internet, as well as the level of information and communication technologies development (experience of use, meeting current needs, security, etc.) is considered as the basis for TLS functioning.

We should emphasize that the leading countries are investing in the development of $4 \mathrm{G}$ and $5 \mathrm{G}[10]$, and fiber-optic networks. Investments in cloud infrastructure have also increased. The development of new information and communication technologies, the Internet of things and artificial intelligence are being stimulated. At the same time, we can observe a high level of mobile Internet penetration, and almost every home has access to the Internet.

The leading countries concentrate their efforts on the creation of secure Internet servers [3], ensuring the transition of information systems to Web 2.0 (3.0), and intensive work in the field of installing devices for the Internet of things systems is underway. Investments in new generation software are growing; information and communication technologies (ICT) are being popularized, in particular the use of Internet of things analytics, analytic scalability and cybersecurity education. ICT business models are also being actively elaborated, a lot of attention being paid to training, patent work and research and development (R\&D).

With the general trend to digitalization, two ways of development and adoption of autonomous vehicles can be identified [6]:

- vehicle machine learning in the context of interaction with pedestrians and stationary objects, decision-making centers being developed, etc.

- enhancing the infrastructure with accounting and information systems when combined with ITS, which today are lagging behind since both bringing the current infrastructure into a normative form and creating a new digital and intelligent infrastructure of the world level assume high costs.

The most famous companies that develop highly automated vehicles are Tesla, Nissan, Volvo, Audi, Google, Apple, Yandex, etc.

Here is the rating of countries that are most prepared for the emergence and adoption of autonomous driving technologies (Table 1). 
Table 1. Countries' readiness to adopt highly automated vehicles

\begin{tabular}{|c|c|c|c|c|}
\hline $\begin{array}{l}\text { Country and overall } \\
\text { ranking, } 2020 \Gamma \text {. }\end{array}$ & $\begin{array}{l}\text { Policy and } \\
\text { Legislation }\end{array}$ & $\begin{array}{l}\text { Technologies } \\
\text { and } \\
\text { Innovations }\end{array}$ & Infrastructure & $\begin{array}{l}\text { Consumer } \\
\text { acceptance }\end{array}$ \\
\hline 1. Singapore & 1 & 11 & 5 & 1 \\
\hline 2. Netherlands & 3 & 10 & 1 & 7 \\
\hline 3. Norway & 10 & 5 & 3 & 5 \\
\hline 4. USA & 6 & 2 & 9 & 6 \\
\hline 5. Finland & 4 & 8 & 11 & 2 \\
\hline 6. Sweden & 15 & 6 & 8 & 3 \\
\hline 7. South Korea & 16 & 7 & 2 & 10 \\
\hline 8. UAE & 8 & 22 & 4 & 4 \\
\hline 9.UK & 2 & 9 & 16 & 12 \\
\hline 10. Denmark & 12 & 15 & 10 & 8 \\
\hline 11. Japan & 18 & 3 & 6 & 18 \\
\hline 12. Canada & 9 & 13 & 13 & 13 \\
\hline 13. Taiwan & 13 & 14 & 14 & 15 \\
\hline 14.Germany & 7 & 4 & 19 & 21 \\
\hline 15. Australia & 17 & 17 & 12 & 9 \\
\hline 16. Israel & 19 & 1 & 25 & 11 \\
\hline 17. New Zealand & 5 & 19 & 20 & 14 \\
\hline 18. Austria & 11 & 16 & 7 & 24 \\
\hline 19.France & 14 & 12 & 17 & 19 \\
\hline 20.China & 21 & 20 & 22 & 16 \\
\hline 21.Belgium & 20 & 18 & 18 & 23 \\
\hline 22. Spain & 23 & 23 & 15 & 17 \\
\hline 23. Czech Republic & 22 & 25 & 24 & 22 \\
\hline 24.Italy & 27 & 21 & 23 & 26 \\
\hline 25. Hungary & 25 & 24 & 21 & 28 \\
\hline 26. Russia & 26 & 26 & 27 & 20 \\
\hline 27. Chile & 24 & 27 & 26 & 25 \\
\hline
\end{tabular}

We should emphasize that one of the important aspects in ITS implementation is the government support [11], which today is provided not only in the form of funding, but also through developing and adopting standards, and helping to organize support activities (procurement, installation, etc.). The latter requires specialists training, use of system engineering methods, etc.

As a result, the formation of TLS today affects many technologies and solutions that are being embodied in finished projects. Yet, their development is only at the initial stage [12]. To form a new type of TLS, it is required:

- first, to improve the interaction of economic agents in the field of development cooperation of a unified management system while integrating into intelligent transportation systems;

- second, to transform the current infrastructure, and massively test highly automated vehicles on public roads;

- third, to design a digital model of the road [13], which can contribute to a more effective coordination of economic agents;

- fourth, to intensify efforts so as to develop end-to-end digital technologies, namely, distributed ledger technologies ensuring data integrity and consistency, data organization and synchronization, as well as creating and executing decentralized applications and smart contracts for TLS.

Today, these technologies are being implemented in financial and insurance spheres, in international logistics in the field of transport, in public administration, in health care, etc. 
They are also used in the aspect of a conceptual-category code and help create interactions between the main spheres of the economy such as production, exchange, distribution and consumption.

At the same time, the creation of a supporting infrastructure and the Internet speed increase are not the only important aspects in the development of a new TLS type. The formation of a multi-agent control system by using Blockchain 2.0 (3.0) technology is also important. Yet, this complex block of research is not fully implemented in the world today.

\section{Results and Discussion}

The generated control system for stream processing operates in P2P networks, which is the next stage in the development of modern information networks. Using smart contracts with the use of distributed ledger technology ensures a higher level of information reliability and a lower need for infrastructure, which is constantly being updated.

The current use of smart contracts lies in the legal field, but the process of their recognition has already started and there are many platforms on which they are being developed (Table 2).

Table 2. Universal Platforms for Smart Contracts Development

\begin{tabular}{|c|c|c|c|c|c|}
\hline Platform & $\begin{array}{c}\text { Consensus } \\
\text { Algorithm }\end{array}$ & $\begin{array}{c}\text { Number of } \\
\text { Transactions, } \\
\text { per second }\end{array}$ & $\begin{array}{c}\text { Public } \\
\text { Network }\end{array}$ & $\begin{array}{c}\text { Competence } \\
\text { Centre }\end{array}$ & $\begin{array}{c}\text { Number of } \\
\text { Contributors }\end{array}$ \\
\hline EOS & D-PoS & Up to 1275 & yes & & 192 \\
\hline Ergo & PoW & - & & yes & 20 \\
\hline Ethereum & PoW & 15 & & yes & 430 \\
\hline Exonum & BFT & 5000 & & & 11 \\
\hline $\begin{array}{c}\text { Hashgraph } \\
\text { Hedera }\end{array}$ & DAG & 10 & yes & & 187 \\
\hline $\begin{array}{c}\text { Hyperledger } \\
\text { Fabric }\end{array}$ & PBFT & 20000 & & yes & 11 \\
\hline ICON & BFT & 9000 & yes & & 38 \\
\hline IOTA & DAG & - & yes & & 4 \\
\hline MultiChain & BFT & 2,5 & yes & & 1 \\
\hline NEM & BFT & 4000 & yes & & 1 \\
\hline OpenChain & BFT & 1000 & yes & & - \\
\hline R3 Corda & BFT & 6300 & yes & & 54 \\
\hline Tezos & PoS & 4000 & yes & & yes \\
\hline Vostok & Various & - & & yes & \\
\hline Waves & PoS & 1000 & yes & & \\
\hline
\end{tabular}

We would like to emphasize that among the important factors in the development of smart contracts are the existence of a public network and a trusted competence center, which ensures the initiation of the platform development, as well as the number of contributors involved in the system design and improvement.

The development of peer-to-peer nodes, including smartphones, personal computers, automated control systems, etc., enables to redistribute the load on the networks and reduce investment in the formation of data processing systems, since the computing power is being combined.

Each node is characterized by its own services, which are to provide the information transfer, processing, analysis, etc. To ensure smart contracts validation and for security reasons, partially or completely decentralized networks are to be developed.

The development of a dynamic infrastructure is ensured by an increasing smartphone penetration rate and a share of households with computers. And the formation of a new 
TLS type eliminates the emerging risks of interaction between economic agents, improves logistics services and provides savings.

For this purpose, it is necessary to reflect the generalized scheme of interaction of economic agents in a peer-to-peer network (Figure 1).

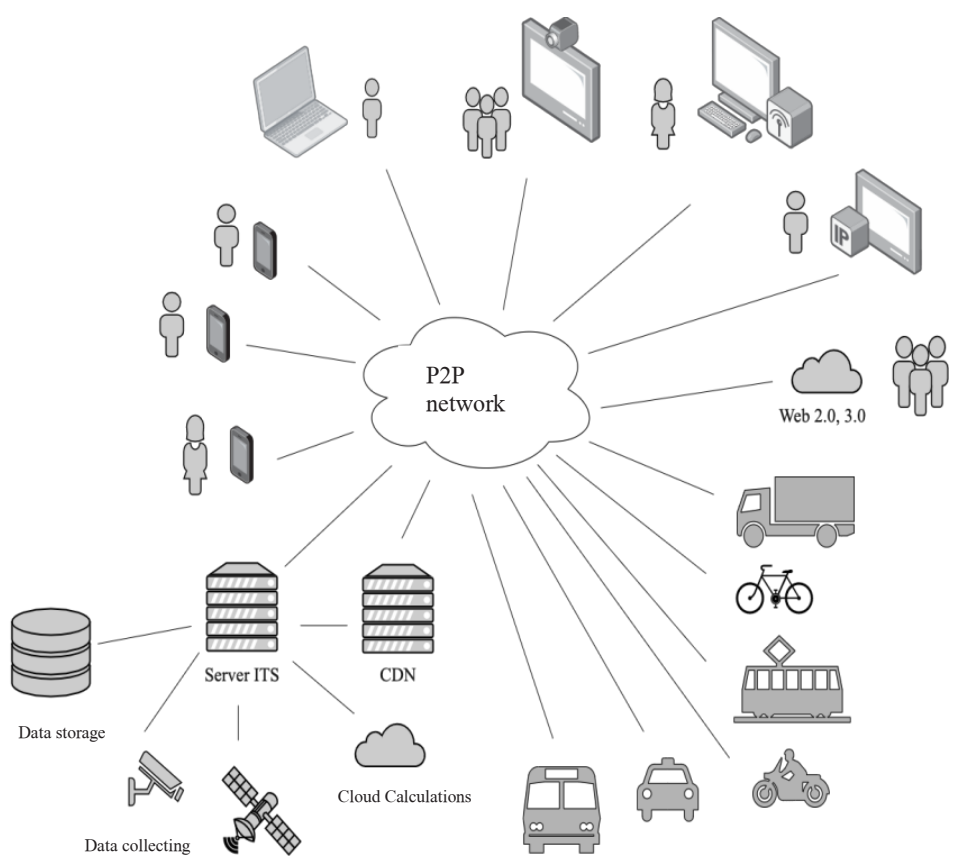

Fig. 1 The scheme of interaction in a network of peer-to-peer TLS nodes

The above infrastructure and means of communication form a single information space for a new TLS type.

Economic agents, when connected through communications, have an opportunity to make an agreement for using any type or combination of vehicles with / without the use of highly automated vehicles on the digital road. In addition, the network provides data collecting, and initiates developments to improve interactions between economic agents.

\section{Conclusion}

Research into the use of low-power systems in the field of smart contracts is nowadays focused on the development of architecture and services, and depend on competence centers and contributors. Yet, to form a new type of TLS for the development of a distributed data network, a speed of $20-50 \mathrm{kbps}$ is sufficient, which corresponds to any economic agent using both broadband and mobile connection in today's environment.

Thus, there is an opportunity to change the current trend of catching-up development and introduce a new author's vision, which will enable to build a new management system and reach a higher level of the system decentralization at a lower transaction cost.

\section{References}

1. T. Qu, M. Thürer, J. Wang, Z. Wang, H. Fu, C. Li, G. Huang, International Journal of Production Research, 55, 2622 (2017) 
2. A. Gessa, P. Sancha, Journal of Urban Technology, 27, 27 (2020)

3. A. Nixa, S. Deckerb, Business History, 04, 1 (2021)

4. M. Attaran, Supply Chain Forum: An International Journal, 21, 158 (2020)

5. X. Jiang, Journal of Chinese Economic and Business Studies, 18, 333 (2020)

6. W. Clayton, D. Paddeu, G. Parkhurst, J. Parkin, Transportation Planning and Technology, 43, 1 (2020)

7. A. Balasubramaniam, J. Gul M., V. G. Menon, A. Paul, IETE Technical Review, 0, 1 (2020).

8. M. Pournader, Y. Shi, S. Seuring, L. Koh, International Journal of Production Research, 58, 2063 (2020)

9. L. Koh, A. Dolgui, J. Sarkis, International Journal of Production Research, 58, 2054 (2020)

10. P. Subedi, A. Alsadoon, P.W.C. Prasad, S. Rehman, N. Giweli, M. Imran, S. Arif, EURASIP Journal on Wireless Communications and Networking, 102 (2021)

11. G. Savin, S. Bronnikov, Business Logistics in Modern Management, 485 (2018)

12. G. Savin, E3S Web of Conferences, 208 (2020)

13. H. Wang, W. Quan, W. Y. Ochieng, Journal of Intelligent Transportation Systems, 24, 480 (2020) 